\title{
A Fuzzy Analytical Hierarchy Process in Innovative Education - An Approach
}

\author{
Sahitya Mondal \\ M. Tech IT (Courseware Engineering) \\ Jadavpur University \\ Kolkata, India
}

\author{
Joydeep Mukherjee \\ Assistant Professor/ Department of SET \\ Jadavpur University \\ Kolkata, India
}

\begin{abstract}
Innovative education is one of the challenging fields in education technology domain. Innovative education helps to train a large number of high quality students to train their respective field. So analyze the quality of innovative education is very important. This research work mainly concentrates on quality analysis of the innovative education using Analytical Hierarchy Process and Fuzzy Comprehensive Evaluation Model. Analytical Hierarchy Process is a multi criteria decision making process that helps to solve complex problems and Fuzzy Comprehensive Evaluation provides grading with respect to the analysis and reviews.
\end{abstract}

\section{General Terms}

Quality Analysis of Innovative Education

\section{Keywords}

Innovative Education, Analytical Hierarchy Process, Fuzzy Comprehensive Evaluation Model, Quality Analysis.

\section{INTRODUCTION}

The education system and its environment should be very friendly as well as interesting in front of the learners. Innovative education is the solution that provides the environment along with the facilities that are very necessary to built future of high quality talents. It motivates the students to do better than the conventional mechanism. Here students get the hands on facility of their work. That helps the students or educators to establish themselves in the organization as well as in society.

So measure the quality [1] of the innovative education is the primary goal of this research work. Quality measurement of innovative education is enhanced the education system in proper way. It helps to find out what are the limitations involving in the system. It helps to recover those problems and evaluate further. Not only that if there is a major problem happening in the system it sends the system for further development. For doing the quality measurement some scientific calculation as well as analysis is needed. That's why this research work needs AHP (Analytical hierarchy Process) \& Fuzzy comprehensive evaluation model. These Scientific analyses help to find out the parameters which are directly related to the educational system. Using the AHP it provides the weight of the each index of the judgment matrix. Fuzzy comprehensive evaluation model provides the fuzzy matrix according to the reviews. These two above methods are used in this research work to measure the quality of the system. The reasons for doing this research work are:

- The total development of innovative education will be systematic.

- The quality of the educational system will be maintained a certain threshold.
- If the quality is not maintaining a certain level then it sends the system for further development.

- This will be cost effective.

In this research work the necessary assumptions are:

- The calculation of judgment matrix is done from analysis.

- The fuzzy evaluating matrix is taken from the analysis with respect to the system.

- The value of the score set is taken with a specific interval.

This paper brings out the standard methodology, calculation and algorithm for determining the quality of innovative education. Section 2 discusses related works for the Analytical Hierarchy Process and its applications and section 3 depicts the idea of standard methodology for quality evaluation of innovative education. Sections 4 shows the algorithm of this research work and 5 shows the way of implementing the algorithm for quality evaluation and results obtained respectively. Section 6 derives the conclusion and future enhancements.

\section{RELATED WORK}

Yan Hezhan [1] introduced Analytical Hierarchy process \& fuzzy comprehensive evaluation model to measure the quality of the innovation education in higher education institution. According to the analysis the hierarchical structure is formed with the desire parameters that have a signification with the innovation education. It described the Analytic Hierarchy Process (AHP) to confirm the weight of each index and construct the judging matrix and confirm the comment set that helps to measure the quality. Here the evaluation matrix $(\mathrm{R})$ is build through the expert reviews and their comments. Finally quality is calculated through the normalization of calculated matrix and the score set. The overall quality of the system helps to decide which parameters of the system need to be taken care to enhance the overall quality.

Xiaojing Liu [2] proposed the index system and determines the index values in order to calculate the proximity between the evaluation index system and the ideal system. The author has implemented the evaluation index system for the quality of undergraduate education and incorporated the AHP method to solve the problem and provides a comprehensive structure by both quantitative and qualitative criteria in the decisionmaking process.

Paweł CABALA [3] proposed a hierarchical structure of a system and pair-wise comparisons to find out the indexes of the system as well as derive and implement of the selection process for the project variant using the AHP. The index system of project variant is calculated through the pair-wise 
comparison. The proposed algorithm is derived to implement the project variant.

Edit Adamcsek [4] proposed work is mainly concentrate on the theory part regarding hierarchical decomposition of decision, pair-wise comparison and pair-wise matrix evaluation and provide the mathematical calculation regarding the problem. This work derives several methods on pair-wise comparison like Eigenvector Method, Least Squares Method and Logarithmic Least Squares Method. It also describes Analytic Network Process (ANP) which is an alternative of AHP. Many complex problems cannot be structured hierarchically because they have strong involvement of interactions and dependencies of higher-level elements with lower level elements. In that case ANP is very efficient.

Alade O. A., Ganiyu R. A., Oladipupo E. T. [5] derived the proper algorithm of AHP and pseudo code that gives a flow of the total implementation. Other than that it derives the pairwise comparison to create the judgment matrix and also mention the consistency of the matrix and calculate the indexes values or the priority vector of the system. These priority vectors are useful to evaluate the total system.

Neethu Fernandes, Rakhi Bhadkamkar [6] proposed work include the structure of the system, calculate the priority vectors of the system, check the consistency and ensure that the matrix is created by the pair-wise comparison is acceptable. This work is given a detail programming to calculate the priority vectors.

Quang Hung Do and Jeng-Fung Chen [7] proposed work on teacher performance which is calculated through the fuzzy analytical hierarchy process. Here first mention the fuzzy set and fuzzy number and take a fuzzy triangular membership function and then developing a Hierarchical Structure of the Evaluation Index System to calculate the consistency and further development. Here teacher performance is calculated based on the student review and scores.

Cheng Zhilong [8] implemented the overall quality evaluation of the index system including grades these are taken as a parameter. It uses AHP to calculate the weight of the parameters. Here evaluation is done for the teacher's comprehensive quality based on their professional ethics, professional ability and professional concept.

R. W. SAATY [9] proposed work describes the necessary steps of Fuzzy Analytical Hierarchical process with two different examples. This approach may helpful to develop applications of the AHP in game theory, implement psychological lessons to show how people's strength of feeling can be represented by the numerical scales.

G.B. Crowford [10] proposed literature has advocated the use of the dominant right eigenvector and an associated consistency ratio. This gives a procedure called geometric mean for estimating the scale of the judgment matrix. Finally it checks the consistency to show that judgment matrix is properly built.

Z. Xu [11] discuss the weighted geometric mean method (WGMM) is the most common group preference aggregation method in the Analytic Hierarchy Process. This paper reports on research concerning the consistency of WGMM and proves that the weighted geometric mean complex judgment matrix (WGMCJM) is maintaining the consistency. It helps to handle the complex problem in simple way.

N. Bhushan and K. Rai [12] literature consists with several decision making technique along with step by step derivation of the analytical hierarchy process. It also takes the ratio scale in order to implement.

\section{PROPOSED METHODOLOGY}

The present paper proposes a scheme for determine the quality of the innovative education using Analytical Hierarchy Process and fuzzy comprehensive evaluation model. Figure 1 describes the overall flow of the proposed methodology.

The section is grouped into five categories: (1) Develop the hierarchical structure (2) Construct the judgment matrix (3) Calculate priorities and consistency checking (4) Establish Fuzzy evaluation matrix \& score set and (5) Quality evaluation

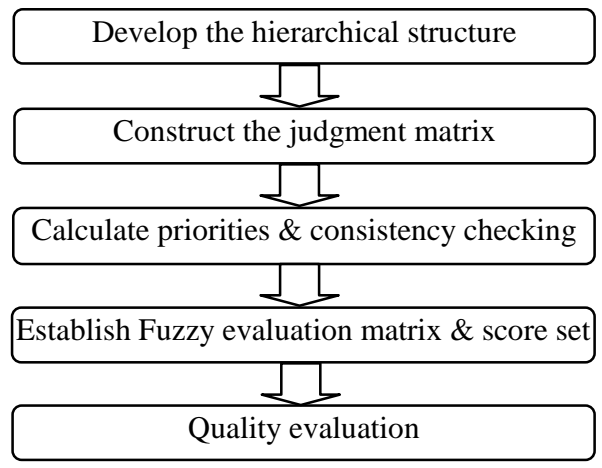

Figure 1: Flow of the proposed methodology

\subsection{Develop the hierarchical structure}

Each and every system has some parameters that have a strong relationship with the system. In order to determine the quality of innovative education, a hierarchical index system should be formed according to the parameters related to the educational system. The hierarchical structure generally has two levels: (a) Primary level index (b) Secondary index level. In case of complex problem there may be more than two levels of hierarchy in that case Analytic Network Process (ANP) [4] should be used instead of AHP. Figure 2 shows the hierarchical structure of innovative education. Here B1, B2, B3 and B4 are primary level indexes and C1, C2, C3 ...C12 are secondary level indexes. Here all the parameters have a strong relationship with educational system.

- Government plays important roles for educational system providing funds for education and its management. Government has also mentioned some policies for educational enhancements.

- University is the temple of the education. It provides a good learning environment and facilities for educators by recruiting professionals.

- Students or educators are the key factor of any educational organization. They are the target of innovative education. Apart from their study they are also busy for doing their research work and others various activities.

- Society also supports for innovative education by providing social reputation and social atmosphere. Apart from that enterprise groups are also arranging workshop programs for students and helps for innovative education 


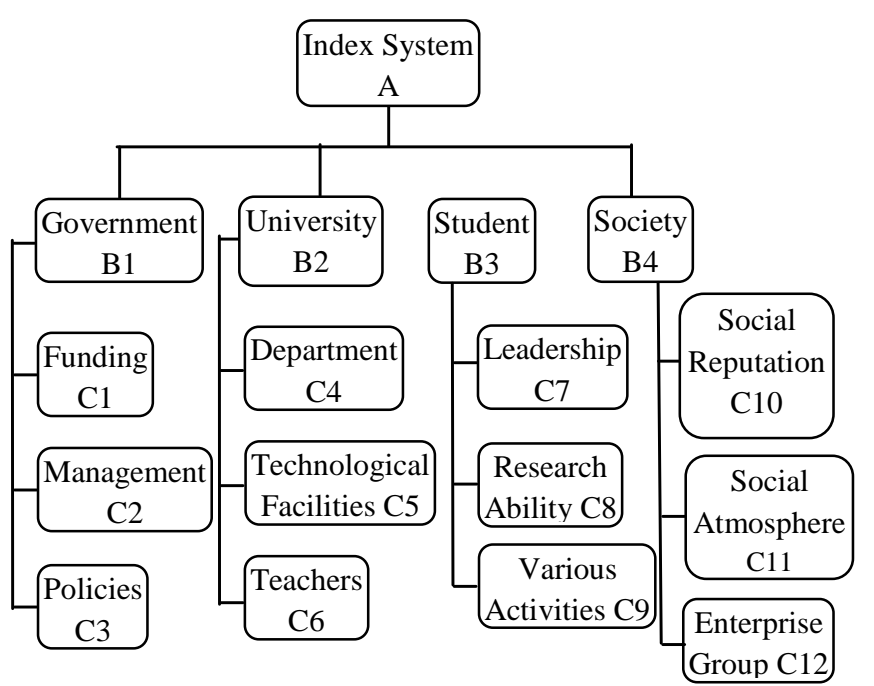

Figure 2: Hierarchical structure of innovative education

\subsection{Construct the judgment matrix}

The AHP method is based on the use of pair-wise comparisons, which lead to the elaboration of a ratio scale describe in Table 1. In the AHP method, multiplicative preference relations are called judgment matrices, and are adopted to express the decision maker's preferences. The pairwise comparisons constitute square matrices, as shown in the [3] Figure 3, the values of elements are between [3] 1/9 and 9.

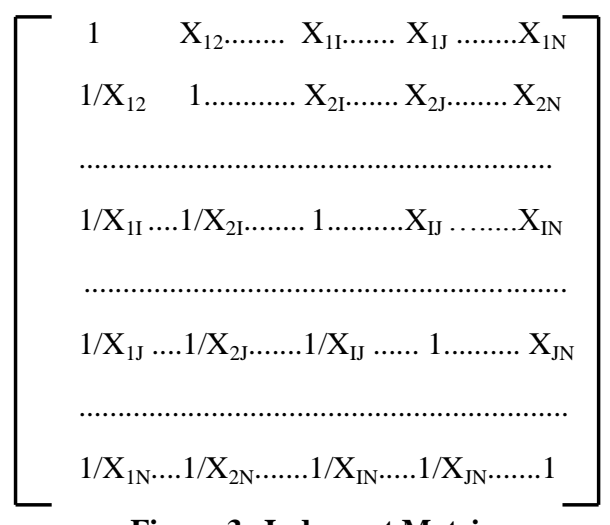

Figure 3: Judgment Matrix

If total numbers of primary level indexes are $n$, then total numbers of significant elements: $n(n-1) / 2$.

For example if total number of primary level indexes are 4 , then significant elements: $4(4-1) / 2=6$.

Others elements will be the reciprocal of significant elements.

Table 1. Evaluation scale used in pair-wise comparison

\begin{tabular}{|c|c|}
\hline Intensity of importance & Definition \\
\hline 1 & Equal importance \\
\hline 3 & Moderate importance \\
\hline 5 & Strong Importance \\
\hline 7 & Very strong importance \\
\hline
\end{tabular}

\begin{tabular}{|c|c|}
9 & Extreme importance \\
\hline $2,4,6,8$ & Between the above values \\
\hline
\end{tabular}

\subsection{Calculate priorities \& consistency checking}

The pair-wise comparison is using to find out the judgment matrix of primary index level as well as secondary index level parameters. Calculate the weight or priorities of each judgment matrix are necessary for this research work. Figure 4 shows a general form of judgment matrix and with help of this matrix the formula is derived to calculate priorities.

$\mathbf{A}_{1}$
$\mathbf{A}_{2}$
$\mathbf{A}_{3}$
$\mathbf{A}_{4}$$\left[\begin{array}{cccc}1 & \mathbf{A}_{\mathbf{1}} & \mathbf{A}_{3} & \mathbf{A}_{4} \\ 1 / \mathrm{B} 21 & 1 & \mathrm{~B} 13 & \mathrm{~B} 14 \\ 1 / \mathrm{B} 31 & 1 / \mathrm{B} 32 & 1 & \mathrm{~B} 34 \\ 1 / \mathrm{B} 41 & 1 / \mathrm{B} 42 & 1 / \mathrm{B} 43 & 1\end{array}\right]$

Figure4: General form of judgment matrix

- Weight(W') or priorities calculation[1]:

$\mathrm{W}_{\mathrm{ij}}=\mathrm{A}_{\mathrm{ij}} / \sum \mathrm{A}_{\mathrm{kj}}[\mathrm{i}=0$ to $\mathrm{n} ; \mathrm{j}=0$ to $\mathrm{n} ; \mathrm{k}=0$ to $\mathrm{n}]$

Above operation is done with the Figure 4 matrix then a new matrix (w) will be formed then,

$\mathrm{W}_{\mathrm{i}}{ }^{\prime}=\sum \mathrm{w}_{\mathrm{ij}} / \mathrm{n} \quad[\mathrm{i}=0$ to $\mathrm{n} ; \mathrm{j}=0$ to $\mathrm{n}$ ]

$\mathrm{W}^{\prime}=\left(\mathrm{W}^{\prime} 1, \mathrm{~W}_{2}^{\prime}, \mathrm{W}_{3}^{\prime}, \mathrm{W}_{4}\right)^{\mathrm{T}}$

So derived weight of Figure 4 matrix is W'.

- Consistency checking[5]:

The judgment matrix has created with pair-wise comparison must have Consistency Ratio (C.R.) less than 0.1 then only the matrix is acceptable, otherwise the matrix need to reform.

Consistency $\left(\mathrm{C}_{\mathrm{i}}\right)$ of the matrix:

$\mathrm{C}_{\mathrm{i}}=\operatorname{MATMULT}\left(\mathrm{A}_{\mathrm{i}}, \mathrm{W}_{\mathrm{j}}\right)[\mathrm{i}=0$ to $\mathrm{n} ; \mathrm{j}=0$ to $\mathrm{n}]$

so, $\mathrm{C}_{\mathrm{i}}=\mathrm{C}_{1}, \mathrm{C}_{2}, \mathrm{C}_{3}, \ldots . \mathrm{C}_{\mathrm{n}}[\mathrm{i}=0$ to $\mathrm{n}]$

$\lambda_{\max }=\sum \mathrm{C}_{\mathrm{i}} / \mathrm{n}$

Value of the Consistency Index (C.I.) $=\left(\lambda_{\max }-n\right) /(n-1)$

Consistency Ratio (C.R.) = C.I. /R.I. [R.I. value will get from Table 2]

Table 2. Random Index (R.I.) Value [5]

\begin{tabular}{|c|c|c|c|c|c|c|c|c|c|}
\hline $\mathrm{N}$ & 1 & 2 & 3 & 4 & 5 & 6 & 7 & 8 & 9 \\
\hline R.I. & 0.00 & 0.00 & 0.58 & 0.90 & 1.12 & 1.24 & 1.32 & 1.41 & 1.45 \\
\hline
\end{tabular}

C.R. value must be 0.1 then only the matrix is acceptable.

\subsection{Establish Fuzzy evaluation matrix \& score set}

Fuzzy evaluation matrix is formed through the analysis. This is used for evaluating the system. 


$$
\mathrm{R}=\left[\begin{array}{ccc}
\mathrm{R}_{11} & \mathrm{R}_{12} \ldots \ldots & \mathrm{R}_{1 \mathrm{n}} \\
\mathrm{R}_{21} & \mathrm{R}_{22} \ldots \ldots . \mathrm{R}_{2 \mathrm{n}} \\
\ldots \ldots \ldots \ldots \ldots \ldots \ldots \ldots \ldots \ldots \ldots \ldots \ldots \ldots & \ldots \ldots \\
\mathrm{R}_{\mathrm{m} 1} & \mathrm{R}_{\mathrm{m} 2} \ldots . & \mathrm{R}_{\mathrm{mn}}
\end{array}\right]
$$

Figure 5: Fuzzy evaluation matrix[1]

$R_{i j}(i=1$ to $m ; j=1$ to $n$ ) means the subordinate degree of factor index $R_{i}$ to the $V_{j}$ comment.

The score set is assumed as $\mathrm{K}$ and $\mathrm{K}=\left(\mathrm{K}_{1}, \mathrm{~K}_{2}, \mathrm{~K}_{3}, \ldots \ldots . \mathrm{K}_{\mathrm{n}}\right)^{\mathrm{T}}$ $\mathrm{K}_{\mathrm{i}}=\mathrm{i} * 100 / \mathrm{n}(\mathrm{i}=1,2, \ldots \ldots \mathrm{m})$

If the full marks is 100 then, $K=[20,40,60,80,100]$

Table 3. Score set [1]

\begin{tabular}{|c|c|c|c|c|c|}
\hline $\begin{array}{c}\text { Score } \\
\text { Range }\end{array}$ & {$[0-60)$} & {$[60-70)$} & {$[70-80)$} & {$[80-90)$} & {$[90-100]$} \\
\hline Comments & Bad & $\begin{array}{c}\text { Little } \\
\text { Bad }\end{array}$ & Medium & $\begin{array}{c}\text { Little } \\
\text { Good }\end{array}$ & Good \\
\hline
\end{tabular}

\subsection{Quality evaluation}

The quality is measured with priorities, score set and fuzzy evaluation matrix.

\section{4PROPOSED ALGORITHM}

I. Create the hierarchical structure.

II. Create judgment matrix for each indexes.

III. Taking each matrix:

Loop $(\mathrm{i}=0 ; \mathrm{i}<\mathrm{n} ; \mathrm{i}++)$

\section{SUM (Total elements of the $i$ th Column).}

Divide each elements of the matrix with the SUM.

IV. Taking the new matrix:

Loop $(\mathrm{i}=0 ; \mathrm{i}<\mathrm{n} ; \mathrm{i}++)$

\section{SUM (Total elements of the $i$ th Row)}

Divide SUM with total elements of the $i$ th Row.

Get priorities in form of a matrix.

V. Taking the new matrix:

Loop $(\mathrm{i}=0 ; \mathrm{i}<\mathrm{n} ; \mathrm{i}++)$

Take the ith row of the judgment matrix as A.

Take the transpose of the priorities matrix as B.

Determine the Consistency $\mathrm{C}_{\mathrm{i}}=(\mathrm{A} * \mathrm{~B}) / \mathrm{n}$

Calculate $\lambda_{\max }=\sum \mathrm{C}_{\mathrm{i}} / \mathrm{n}$

Calculate Consistency Index (C.I.) $=\left(\lambda_{\max }-n\right) /(n-1)$

Calculate Consistency Ratio (C.R.) = C.I. /R.I.

$$
\text { If }(\text { C.R. }<0.1)
$$

Judgment matrix is acceptable.

Else

Judgment matrix is not acceptable.

$$
\text { GOTO step II. }
$$

VI. Taking the score set K \& Fuzzy evaluation matrix (R).

VII. Then subordinated vector $\left(\mathrm{R}_{\mathrm{B}}\right)=[$ MATMULT $\left\{(\text { secondary level priorities })^{\mathrm{T}}\right.$, Fuzzy evaluation matrix $\left.\}\right]^{\mathrm{T}}$.

VIII. Then the Comprehensive evaluation model (A) = MATMULT[(primary weights) $\left.{ }^{\mathrm{T}}, \mathrm{R}_{\mathrm{B}}\right]$.

IX. Then normalizes the result by dividing each element of A with the sum of all elements and get A'.

X. Finally Quality can be obtain through A' * K.

\section{RESULTS}

\begin{tabular}{|c|c|c|c|c|c|c|c|c|}
\hline JUDGEMENT MATRIX & B1 & B2 & B3 & B4 & 85 & B6 & B7 & B8 \\
\hline BI & 1 & 0.33 & 3 & 5 & & a & 0.0775 & \\
\hline B2 & 3 & 1 & 7 & 5 & & RI & 0.9 & \\
\hline B3 & 0.33 & 0.14 & 1 & 3 & & CR & 0.0861 & \\
\hline$B 4$ & 0.2 & 0.2 & 0.33 & 1 & & & & \\
\hline$B 5$ & & & & & & LAMDA(MAX) & 4.2325 & \\
\hline B6 [TOTAL] & 4.53 & 1.67 & 11.33 & 14 & & & & \\
\hline B7 & & & & & & TOTAL & WEIGHTS & CONSISTENC \\
\hline B8 & 0.2208 & 0.1976 & 0.2648 & 0.3571 & & 1.0403 & 0.260075 & 4.3 \\
\hline B9 & 0.6623 & 0.5988 & 0.6178 & 0.3571 & & 2.236 & 0.559 & 4.42 \\
\hline 810 & 0.0728 & 0.0838 & 0.0883 & 0.2143 & & 0.4592 & 0.1148 & 4.16 \\
\hline B11 & 0.0442 & 0.1198 & 0.0291 & 0.0714 & & 0.2645 & 0.066125 & 4.05 \\
\hline B13 [TOTAL] & 1.0001 & 1 & 1 & 0.9999 & & & & \\
\hline
\end{tabular}

All the calculations of this research work are shown in Figure 6 to10.

\begin{tabular}{|c|c|c|c|c|c|c|c|c|}
\hline JUDGEMENT MATRIX & B1 & $B 2$ & Bз & B4 & B5 & B6 & B7 & B8 \\
\hline BI & 1 & 3 & 5 & & & a & 0.018333 & \\
\hline B2 & 0.33 & 1 & 3 & & & RI & 0.58 & \\
\hline B3 & 0.2 & 0.33 & 1 & & & CR & 0.0316 & \\
\hline \multicolumn{9}{|l|}{$B 4$} \\
\hline \multicolumn{5}{|l|}{$B 5$} & & LAMDA(MAX) & 3.036667 & \\
\hline B6 [TOTAL] & 1.53 & 4.33 & 9 & & & & & \\
\hline \multicolumn{5}{|l|}{$B 7$} & & TOTAL & WEGHTS & CONSISTENCY \\
\hline$B 8$ & 0.6536 & 0.6928 & 0.5556 & & & 1.902 & 0.634 & 3.07 \\
\hline B9 & 0.2157 & 0.2309 & 0.3333 & & & 0.7799 & 0.259967 & 3.03 \\
\hline$B 10$ & 0.1307 & 0.0762 & 0.1111 & & & 0.318 & 0.106 & 3.01 \\
\hline \multicolumn{9}{|l|}{$B 11$} \\
\hline B13 [TOTAL] & 1.0001 & 1 & 1 & & & & & \\
\hline
\end{tabular}

Figure 6: Weight calculation of primary level indexes

Figure 7: Secondary level weight calculation(Government)

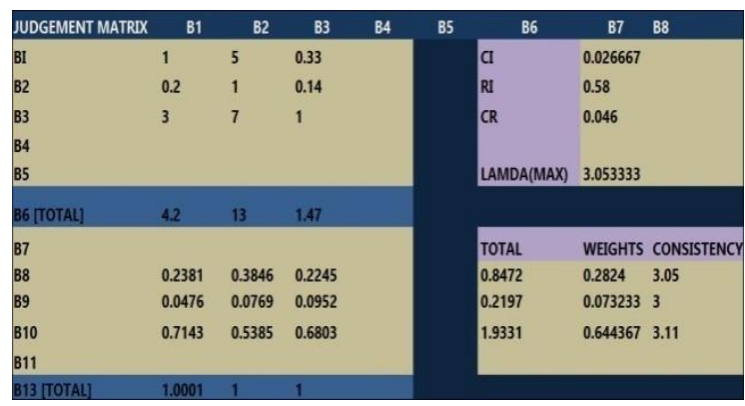

Figure 8: Secondary level weight calculation (University) 


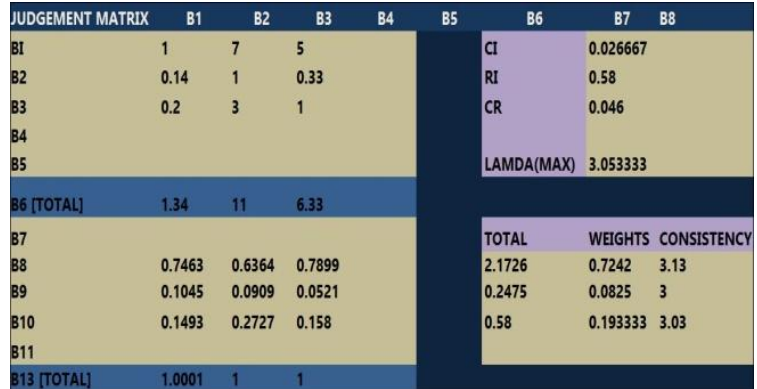

Figure 9: Secondary level weight calculation (Student)

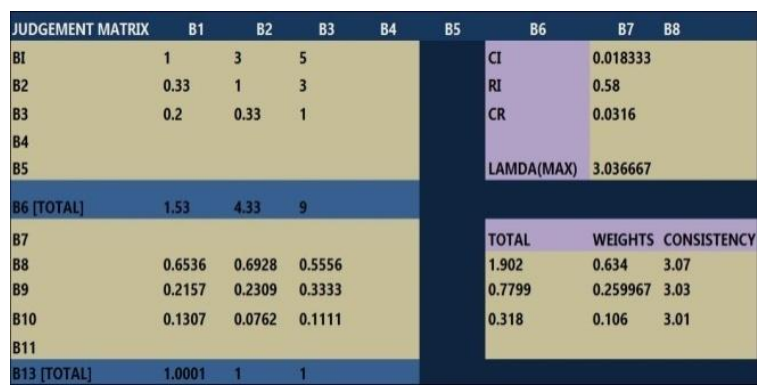

Figure 10: Secondary level weight calculation (Society)

Based on the calculation from Figure 6-10 the weights of the primary level indexes are :

$\mathrm{W}^{\prime}=(0.260425,0.558725,0.114775,0.06605)^{\mathrm{T}}$

The weights of secondary level indexes are:

$\mathrm{W}^{\prime}{ }_{1}=(0.6333,0.26,0.10666)^{\mathrm{T}}$

$\mathrm{W}_{2}^{\prime}=(0.28,0.07666,0.643333)^{\mathrm{T}}$

$\mathrm{W}_{3}{ }_{3}=(0.72666,0.08,0.19333)^{\mathrm{T}}$

$\mathrm{W}^{\prime}{ }_{4}=(0.63333,0.26,0.1066)^{\mathrm{T}}$

Table 4 describes the fuzzy evaluation matrix (FM) based on the analysis and reviews.

Table 4: Fuzzy evaluation matrix [1]

Index Good Little Good Medium Little bad Bad

\begin{tabular}{|c|c|c|c|c|}
\hline \multirow{3}{*}{ 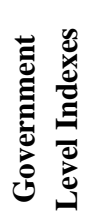 } & 0 & 0 & 0.4 & 0.6 \\
\hline & 0 & 0 & 0.4 & 0 \\
\hline & 0 & 0.4 & 0.4 & 0.2 \\
\hline \multirow{3}{*}{ 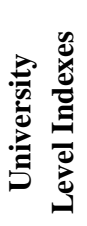 } & 0 & 0.4 & 0.2 & 0 \\
\hline & 0 & 0.2 & 0.4 & 0.2 \\
\hline & 0 & 0.4 & 0 & 0 \\
\hline \multirow{3}{*}{ 总 } & 0 & 0 & 0 & 0.4 \\
\hline & 0 & 0.6 & 0.4 & 0 \\
\hline & 0 & 0 & 0 & 0.8 \\
\hline & 0 & 0 & 0 & 0.4 \\
\hline
\end{tabular}

$$
\begin{array}{ccccc}
0 & 0.4 & 0.2 & 0 & 0.4 \\
0 & 0.2 & 0 & 0.2 & 0.6
\end{array}
$$

Then calculate the Subordinated vector $\left(\mathrm{R}_{\mathrm{B}}\right)$ by multiplying the secondary weights with the corresponding Fuzzy evaluation matrix.

Then calculate the Subordinated vector $\left(R_{B}\right)$ by multiplying the secondary weights with the corresponding Fuzzy evaluation matrix. So, $\mathrm{R}_{\mathrm{B}}=$

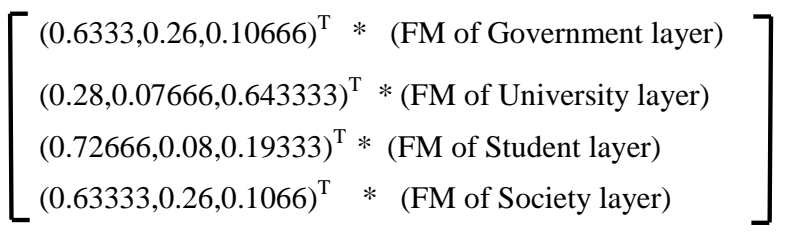

$=$

$\left[\begin{array}{lllll}0 & 0.0424 & 0.4 & 0.4016 & 0.156 \\ 0.147 & 0.3853 & 0.0565 & 0 & 0.5435 \\ 0 & 0.0495 & 0.0330 & 0.4443 & 0.4732 \\ 0 & 0.1252 & 0 & 0.3268 & 0.5480\end{array}\right]$

Then the comprehensive evaluation model(A) is derived by multiplying primary level weights(W') with subordinated vector $\left(\mathrm{R}_{\mathrm{B}}\right)$

$\mathrm{A}=\mathrm{W}^{\prime} * \mathrm{R}_{\mathrm{B}}=\mathrm{A}=(0.0082,0.2404,0.1394,0.1771,0.4350)$

Then normalized the A value by dividing the each element with sum of the total elements.

SUM $=(0.0082+0.2404+0.1394+0.1771+0.4350)=1.0001$

$\mathrm{A}^{\prime}=(0.0082 / \mathrm{SUM}, 0.2404 / \mathrm{SUM}, 0.1394 / \mathrm{SUM}$, $0.1771 /$ SUM, $0.4350 /$ SUM)

$\mathrm{A}^{\prime}=(0.0082,0.2404,0.1394,0.1771,0.4350)$

Putting the score set value $\mathrm{K}=(20,40,60,80,100)^{\mathrm{T}}$

Finally quality $(\mathrm{B})$ of the system is obtained by $\mathrm{A}^{\prime} * \mathrm{~K}$

So, $\mathrm{B}=\left[\begin{array}{lllll}0.0082 & 0.2404 & 0.1394 & 0.1771 & 0.4350\end{array}\right]$ * [20 406080 $100]^{\mathrm{T}}=75.80$

\section{CONCLUSIONS AND FUTURE WORK}

According to the result the quality of the innovative education system is not up to the mark. The quality is measured with the help of fuzzy evaluation matrix which is made through the analysis and reviews. So, it can be happen that the quality may vary in real scenario. To enhance the quality of innovation education, the educational system needs better inputs and supports and also needs to improve the aspects which are directly related to the educational system. In this research work the quality of the innovative education is calculated based on the certain parameters which are directly related to the innovative education. The judgment matrix of each parameter is created according to analysis based on the analytical hierarchy process (AHP). The score set is taken as randomly based on a certain interval. In future any author can extent the work with better approach and methods and implement the fuzzy evaluation matrix with artificial 
intelligence which will definitely save time and will provide a innovative way of evaluating the system.

\section{REFERENCES}

[1] Yan Hezhan , "Application of Fuzzy Analytical Hierarchy Process in Innovation Education Quality Evaluation of Higher Education Institution”, 2012 International Conference on Information Management, Innovation Management and Industrial Engineering .

[2] Xiaojing Liu , " An evaluation index system of undergraduate education quality based on an analytic hierarchy process model " World Transactions on Engineering and Technology Education Vol.11, No.4, 2013 .

[3] Paweł CABAŁA, "Using the analytic hierarchy process in evaluating decision alternatives " operations research and decisions , 2010.

[4] Edit Adamcsek, "The Analytic Hierarchy Process and its Generalizations" EÄotvÄos Lorand University , 2008.

[5] Alade O. A., Ganiyu R. A., Oladipupo E. T. , "A Designed Paradigm for Contestant Quality Evaluation using Analytic Hierarchy Process" ,INTERNATIONAL JOURNAL OF SCIENTIFIC \& TECHNOLOGY RESEARCH VOLUME 3, ISSUE 5, May 2014.

[6] Neethu Fernandes, Rakhi Bhadkamkar , “ Scilab Programming for Solving Problems of Multi Attribute Decision Making Using Analytical Hierarchical Process (AHP) Scilab Programming for Solving Problems of Multi Attribute Decision Making Using Analytical Hierarchical Process (AHP)", International Journal of Scientific Engineering and Research (IJSER) .

[7] Quang Hung Do and Jeng-Fung Chen , “ An Evaluation of Teaching Performance: The Fuzzy AHP and Comprehensive Evaluation Approach" ,WSEAS TRANSACTIONS on INFORMATION SCIENCE and APPLICATIONS.
[8] Cheng Zhilong, "Using Delphi method and AHP for the research on Kindergarten teachers' comprehensive quality evaluation index weight", Journal of Chemical and Pharmaceutical Research, 2014, 6(4):6-13.

[9] R. W. SAATY, “ THE ANALYTIC HIERARCHY PROCESS-WHAT IT IS AND HOW IT IS USED ”, Mat/d Modelling, Vol. 9, No. 3-5, pp. 161-176, 1987 Printpd in Great Britain.

[10] G.B. Crowford , “ THE GEOMETRIC MEAN PROCEDURE FOR ESTIMATING THE SCALE OF A JUDGEMENT MATRIX? " , Math/ Modelling. Vol. 9, No. 3-5, pp. 327-334, 1987 Printed in Great Britain .

[11] Z. Xu , "On consistency of the weighted geometric mean complex judgement matrix in AHP ", European Journal of Operational Research 126 (2000) 683 - 687.

[12] N. Bhushan and K. Rai , "Strategic decision making applying the analytic hierarchy process", 2014.

[13] "The Analytic Hierarchy Process (AHP)", International Hellenic University Paraskevopoulos Konstantinos.

[14] http://rad.ihu.edu.gr/fileadmin/labsfiles/decision_support _systems/lessons/ahp/AHP_Lesson_2.pdf

[15] Khwanruthai BUNRUAMKAEW , “ How to do AHP analysis in Excel"

[16] https://www.scribd.com/document/136984385/How-toDo-AHP-Analysis-in-Excel

[17] Kardi Teknomo “ ANALYTIC HIERARCHY PROCESS (AHP) TUTORIAL".

[18] www.thecourse.us/5/library/AHP/AHP_Tutorial.pdf

[19] https://en.wikipedia.org/wiki/Analytic_hierarchy_process

[20] http://bpmsg.com/ahp-online-calculator/. 